\title{
Eliminación de nitrógeno y contaminación orgánica de agua residual industrial pretratada en lagunas anaeróbicas mediante un biofiltro de arena
}

\author{
Rodny Peñafiel $^{1 *}$, Carla Moreno ${ }^{1}$, Valeria Ochoa-Herrera ${ }^{1}$ \\ Universidad San Francisco de Quito (USFQ), Colegio de Ciencias e Ingeniería, Diego de Robles y Vía Interoceánica, \\ Campus Cumbayá, Casilla Postal 17-1200-841, Quito, Ecuador \\ *Autor principal/Corresponding author,e-mail: rpenafiel@usfq.edu.ec \\ Editado por/Edited by: Eduardo Alba-Cabrera, Ph.D. \\ Recibido/Received: 2016/05/11. Aceptado/Accepted: 2016/12/08. \\ Publicado en línea/Published online: 2016/12/13. Impreso/Printed: 2016/12/27.
}

DOI:http://dx.doi.org/10.18272/aci.v8i1.299

\begin{abstract}
Removal of nitrogen and organic pollutants from industrial wastewater pre-treated in anaerobic ponds by means of a sand biofilter
\end{abstract}

\begin{abstract}
The present study reports the removal of chemical oxygen demand (COD) and nitrogen from palm oil mill effluent (POME) treated in an anaerobic wastewater treatment plant of a palm oil mill located in the province of Esmeraldas, Ecuador. The treated POME was purified in a laboratory system consisting of a sand biofilter where physical-mechanical (turbidity removal), biological aerobic (organic matter and nitrification removal) and anoxic (denitrification) processes took place. The purification system involved a sand biofilter that discharged into a vessel from where water was recirculated to the biofilter. The removal of organic matter and nitrification was achieved through aeration (8$\left.12 \mathrm{~h} \mathrm{~d}^{-1}\right)$, while denitrification occurred during the anoxic period $\left(12-16 \mathrm{~h} \mathrm{~d}^{-1}\right)$. The system was operated for 294 days and reached 41 to $85 \%$ COD removal and 44 to $87 \%$ ammonium removal. Furthermore, a $12 \%$ reduction in the total inorganic nitrogen concentration was achieved after the anoxic period compared to the aerobic phase.
\end{abstract}

Keywords. industrial wastewater, crude palm oil, sand biofilter, nitrification, denitrification, COD removal, ammonium removal, aerobic, anoxic.

\section{Resumen}

La presente investigación trata sobre la eliminación de carga orgánica y nitrógeno del efluente tratado en lagunas anaeróbicas de una extractora de aceite crudo de palma africana, ubicada en la provincia de Esmeraldas, Ecuador. El efluente se purificó en un sistema de laboratorio que consiste en un biofiltro de arena, donde ocurren procesos mecánicos (remoción de la turbidez), biológicos aerobios (eliminación de materia orgánica y nitrificación) y anóxicos (desnitrificación). El sistema consiste en un biofiltro de flujo continuo que descarga a un recipiente de donde se recircula el agua al biofiltro. La remoción de materia orgánica y nitrificación se realizó en intervalos de aireación $\left(8-12 \mathrm{~h} \mathrm{~d}^{-1}\right)$, mientras que la desnitrificación ocurrió en el intervalo de no aireación (12-16 h d $\left.{ }^{-1}\right)$. El sistema operó durante 294 días y se logró una remoción de 41 a $85 \%$ de la DQO y 44 a $87 \%$ de amonio. Así mismo se obtuvo un $12 \%$ de reducción en la concentración de nitrógeno inorgánico total después del intervalo de aireación en comparación con el de no aireación.

Palabras Clave. agua residual industrial, aceite crudo de palma, biofiltro de arena, nitrificación, desnitrificación, remoción de DQO, remoción de amonio, aerobio, anóxico. 


\section{Introducción}

La extracción de aceite crudo de palma puede generar impactos ambientales en el agua, suelo y aire, así como pérdida de biodiversidad [1]. Algunos de los aspectos ambientales más importantes son el uso adecuado del agua y el tratamiento del agua residual previo a su descarga [2]. En esta industria se pueden identificar los siguientes procesos con un alto uso de agua: 1) digestión de la fruta de palma mediante vapor de agua con la generación de agua residual de digestión, 2) prensado de la fruta digerida que produce licor de prensa, 3) tamizado del licor de prensa, donde se separan las partículas suspendidas y el líquido filtrado pasa a un clarificador, 4) en el clarificador se separan el aceite y agua por diferencia de densidades, y el aceite clarificado se lleva a un proceso de secado, y 5) la fase acuosa pasa a una centrífuga para recuperar el aceite restante. En este último proceso se genera principalmente el agua residual que pasa a la planta de tratamiento de aguas residuales, efluente conocido como POME (palm oil mill effluent) [1]. Este efluente presenta: elevado contenido de materia orgánica con una demanda química de oxígeno (DQO) de alrededor de $50000 \mathrm{mg} \mathrm{L}^{-1}$, temperaturas entre 80$90^{\circ} \mathrm{C}, \mathrm{pH}$ ácido de alrededor de 4.7, sólidos totales (ST) con valores de hasta $40500 \mathrm{mg} \mathrm{L}^{-1}$, grasas y aceites alrededor de $4000 \mathrm{mg} \mathrm{L}^{-1}$, y Nitrógeno Total Kjeldahl (TKN) de $750 \mathrm{mg} \mathrm{L}^{-1}$ [2]. Las características de este efluente residual pueden generar una serie de problemas al ser descargada a un cuerpo de agua dulce. Una elevada concentración de materia orgánica y temperatura pueden limitar la disponibilidad de oxígeno para los organismos vivos [3]. Así mismo el alto contenido de sólidos pueden generar sedimentos y la presencia aceites y grasas dificultan la transferencia de oxígeno en los cuerpos de agua. La acidificación de los ecosistemas acuáticos reduce la capacidad fotosintética de las algas, favorece la bioacumulación de aluminio y elementos trazas en macrófitos acuáticos, crustáceos, peces y anfibios [4]. El alto contenido de nutrientes del agua residual: nitrógeno en forma orgánica, de amonio $\left(\mathrm{N}-\mathrm{NH}_{4}^{+}\right)$, nitrato $\left(\mathrm{N}-\mathrm{NO}_{3}^{-}\right)$o nitrito $\left(\mathrm{N}-\mathrm{NO}_{2}^{-}\right)$y fósforo (orgánico o inorgánico) pueden generar eutrofización en lagos y ríos [4].

El sistema de tratamiento de aguas residuales de la industria extractora de aceite crudo de palma está compuesto por 9 lagunas (Lagunas 1 a 5 son anaerobias y Lagunas 6 a 9 son facultativas) y fue descrito y analizado en estudios anteriores $[19,20]$. La Laguna 4 muestra condiciones anaeróbicas que promueven el crecimiento de bacterias metanogénicas las cuales generan $115 \mathrm{~m}^{3}$ $\mathrm{d}^{-1}$ de biogás. La Laguna 5 presenta una generación de biogás mucho menor de $16.7 \mathrm{~m}^{3} \mathrm{~d}^{-1}$ y las siguientes lagunas lo generan mínimamente [19]. Ya que en las Lagunas 4 y 5 finaliza el tratamiento anaeróbico del agua, se escogieron estas aguas residuales para ser depuradas mediante el biofiltro del presente estudio. En el trabajo realizado por Narváez [20], el mismo biofiltro fue ali- mentado con el efluente de la Laguna $9($ DQO $=509$ $\left.\mathrm{mg} \mathrm{L}^{-1} ; \mathrm{N}-\mathrm{NH}_{4}^{+}=52 \mathrm{mg} \mathrm{L}^{-1}\right)$. Esta alimentación tiene aireación constante, por lo que el sistema permanece oxigenado (OD sobre $2 \mathrm{mg} \mathrm{L}^{-1}$ ). El biofiltro presenta elevada remoción de carga orgánica (remoción de DQO de $61 \%$ ) y de amonio (remoción de amonio cercana al $100 \%)$. Sin embargo, en el efluente se genera una elevada concentración de nitrato $\left(\mathrm{NO}_{3}^{-}=267 \mathrm{mg}\right.$ $\mathrm{L}^{-1}$ ) debido al proceso de nitrificación.

El proceso de nitrificación es realizado por bacterias quimiolitoautótrofas que emplean carbono inorgánico como fuente de carbono para la síntesis celular y el nitrógeno amoniacal para obtener energía [4]. La nitrificación consta de dos etapas, en la primera el nitrógeno en forma de amonio es oxidado a nitrito (bacterias de género Nitrosomas), seguida de una segunda etapa en la que éstos son oxidados a nitratos (bacterias de género Nitrobacter), (Ecuación 1) [3].

$$
\mathrm{NH}_{4}^{+}+2 \mathrm{O}_{2} \rightarrow \mathrm{NO}_{3}^{-}+\mathrm{H}_{2} \mathrm{O}+2 \mathrm{H}^{+}
$$

La velocidad específica de nitrificación depende de la temperatura (óptimo entre 25 y $30^{\circ} \mathrm{C}$ ) y del pH (óptimo alrededor de 8.5) [6]. Al ser una reacción aerobia, la concentración de oxígeno disuelto (OD) debe estar entre 3 y $5 \mathrm{mg} \mathrm{L}^{-1}$ para promover el crecimiento de bacterias nitrificantes, en vista de que se consume alrededor de $4.33 \mathrm{mg}$ de $\mathrm{O}_{2}$ por cada $\mathrm{mg}$ de $\mathrm{NH}_{4}^{+}$oxidado [7]. La relación $\mathrm{C} / \mathrm{N}$ debe ser baja: estudios demuestran inhibición de actividad nitrificante con relaciones de $\mathrm{C} / \mathrm{N}$ sobre 2 o expresado como DQO/N sobre 5.4 [8]. La nitrificación genera una pequeña cantidad de biomasa y consume $7.07 \mathrm{~g}$ de alcalinidad $\left(\mathrm{CaCO}_{3}\right)$ por cada $\mathrm{mg}$ de $\mathrm{NH}_{4}^{+}$oxidado, pudiendo disminuir el valor del $\mathrm{pH}$ por la producción de iones hidrógeno [7]. El aumento de la carga orgánica promueve el rápido crecimiento de bacterias heterótrofas que compiten con las bacterias nitrificantes, limitando la disponibilidad de OD y el espacio en el biofiltro $[8,9]$.

La desnitrificación es un proceso por el cual los nitratos son reducidos a compuestos gaseosos de nitrógeno. Los organismos responsables son bacterias heterótrofas aerobias facultativas que se desarrollan en condiciones anóxicas [3]. Un sistema de tratamiento anóxico se produce en ausencia de oxígeno disuelto, donde se utilizan compuestos oxidados como nitrato y nitrito para las reacciones metabólicas [5]. Las bacterias utilizan el $\mathrm{NO}_{3}^{-}$como aceptor final de electrones y el carbono orgánico del agua residual como donador de electrones [10]. En presencia de oxígeno, los microorganismos tienen preferencia a éste por encima del nitrato y nitrito; en concentraciones de oxígeno mayores a $2 \mathrm{mg} \mathrm{L}^{-1} \mathrm{la}$ desnitrificación se inhibe [10]. Estudios han demostrado desnitrificación óptima en concentraciones de OD entre 0.2 a $0.5 \mathrm{mg} \mathrm{L}^{-1}$ [11]. Para este proceso, los microorganismos necesitan una fuente de carbono orgánico que puede ser materia orgánica contenida en el agua residual o una fuente de carbono externa, (Ecuación 2) [3]. 


$$
5 \mathrm{NO}_{3}^{-}+\mathrm{C}_{6} \mathrm{H}_{12} \mathrm{O}_{6} \rightarrow 2,5 \mathrm{~N}_{2}+6 \mathrm{CO}_{2}+3 \mathrm{OH}^{-}
$$

Los factores que intervienen en el proceso son: la concentración de oxígeno disuelto, la fuente de carbono orgánica, concentración de nitratos, temperatura, potencial de óxido-reducción, y pH [3]. El pH puede estar en un rango de 4 a 9.5 el cual influye en la formación de los productos. En condiciones de $\mathrm{pH}$ ácidas (menor a 6) se produce óxido nítrico, el cual es tóxico para las bacterias. Por encima de 7 se produce óxido nitroso que es reducido inmediatamente a nitrógeno gaseoso [10]. Durante la desnitrificación se produce un aumento en el pH ya que la alcalinidad incrementa y la concentración de ácido carbónico disminuye. Cada $\mathrm{mg}$ de $\mathrm{N}-\mathrm{NO}_{3}^{-}$reducido genera $3.57 \mathrm{mg}$ de alcalinidad, expresada como carbonato de calcio $\left(\mathrm{CaCO}_{3}\right)$ compensando el descenso del pH ocurrido durante la nitrificación [4].

Un factor que interviene en la reducción del nitrato es la relación $\mathrm{C} / \mathrm{N}$, expresada como $\mathrm{DQO} / \mathrm{N}-\mathrm{NO}_{3}^{-}$[12]. Cuando esta relación se encuentra en un rango de 6 a 9 se observa desnitrificación, principalmente a través de la RDNA (Reducción Desasimilativa de Nitrato - Amonio) [13]. Sin embargo, estudios realizados por GhaniyariBenis et al. han encontrado desnitrificación con relaciones de $\mathrm{DQO} / \mathrm{N}-\mathrm{NO}_{3}^{-}$de 3.3 en un reactor de biopelícula anóxica de múltiples etapas, con una alimentación de $3000 \mathrm{mg} \mathrm{L}^{-1}$ de $\mathrm{N}-\mathrm{NO}_{3}^{-}$y $10000 \mathrm{mg} \mathrm{L}^{-1}$ de DQO [14]. Cuando existe limitación de carbono las bacterias heterótrofas producen enzimas que utilizan el $\mathrm{NO}_{2}^{-}$como aceptor final de electrones en lugar del $\mathrm{NO}_{3}^{-}$, impidiendo el consumo de nitrato [12].

Los procesos de nitrificación y desnitrificación pueden operarse mediante cultivos mixtos de bacterias autótrofas y heterótrofas en suspensión, bajo condiciones de operación aerobia y anóxicas [4]. Wuhrmann planteó un sistema de postdesnitrificación en el cual el agua residual se trata en una etapa aerobia y después en una etapa anóxica; la materia orgánica del agua residual se consume en la etapa aerobia por lo cual es necesaria la adición de una fuente de carbono orgánica externa [15]. Posteriormente en 1962, Ludzack y Ettinger plantearon un tratamiento de predesnitrificación denominado Proceso de Ludzack-Ettinger Modificado, en el cual el agua residual se trata primero en una zona anóxica y posteriormente en una zona aerobia, de tal manera que los nitratos llegan por recirculación y se aprovecha la materia orgánica contenida en el agua residual [15].

Se han desarrollado tratamientos biológicos conocidos como biofiltros, los cuales consisten en lechos empacados con un medio poroso a través del cual pasa el agua a ser depurada [16] . El medio sirve como soporte para el crecimiento de los microorganismos, mediante lo cual se pueden realizar simultáneamente la eliminación de materia orgánica, nitrificación, y desnitrificación. Para este tratamiento es necesaria la recirculación del efluente o filtros en serie [17]. En este sistema, el lecho tiene también un efecto filtrante y atrapa los sólidos suspendidos del agua, disminuyendo su turbidez [16].

Los procesos de nitrificación y desnitrificación pueden ocurrir simultáneamente en un único reactor [12] cuando el amonio es oxidado por microorganismos heterótrofos nitrificantes y la reducción de nitrato por microorganismos desnitrificantes [4]. El factor principal que influye en este proceso simultáneo es la concentración de materia orgánica: concentraciones altas provocan la inhibición de bacterias autótrofas nitrificantes, mientras que concentraciones bajas conducen al déficit de donador de electrones para las desnitrificantes [18]. Cuando la relación $\mathrm{DQO} / \mathrm{N}-\mathrm{NO}_{3}^{-}$se encuentra en un rango de 3 a 5 ocurre una desnitrificación incompleta, observando una escasez de carbono [13]. Sin embargo, con relaciones de $\mathrm{DQO} / \mathrm{N}-\mathrm{NO}_{3}^{-}$mayores a 5.4 se observa inhibición en la nitrificación [8]. Para que ocurra una nitrificación heterotrófa y desnitrificación simultánea la relación DQO/N $-\mathrm{NO}_{3}^{-}$debe estar en un rango de 5 a $6[13,8]$. El OD es un parámetro clave: éste se difunde en las capas de flóculos microbianos para el crecimiento de la biopelícula y es consumido por bacterias nitrificantes. Poco a poco, la concentración de oxígeno disminuye y la zona interna de los flóculos pasa a condiciones anóxicas [11]. A bajas concentraciones de OD se suprime la nitrificación, mientras que a altas concentraciones se inhibe la desnitrificación [4]. Sin embargo, en un estudio realizado por Münch se determinó que a concentraciones alrededor de $0.5 \mathrm{mg} \mathrm{L}^{-1}$ de OD las velocidades de nitrificación heterotrófa y desnitrificación son iguales [12].

El objetivo del presente estudio es evaluar el funcionamiento de los procesos de eliminación de materia orgánica y nitrificación que ocurren en el biofiltro de arena para purificar un efluente de mayor carga orgánica (agua residual de las Lagunas 4 y 5) que el que fue estudiado por Narváez [20]. Por otro lado, el régimen de aireación permanente de la alimentación es modificado por un régimen de períodos alternados de aireación y no aireación con el propósito de promover la desnitrificación en el biofiltro y remover el nitrato generado en el proceso de nitrificación.

\section{Métodos}

\section{Toma de muestras de agua residual}

Se tomaron muestras simples de agua residual proveniente de la descarga de las Lagunas 4 y 5 del sistema de tratamiento de la industria extractora de aceite de palma durante un periodo de operación normal de la empresa. Las muestras se conservaron bajo refrigeración para su transporte y posterior uso y análisis en laboratorio. 


\section{Métodos analíticos}

La caracterización del efluente de las Lagunas 4 (L4) y 5 (L5) se realizó de acuerdo a los protocolos del Laboratorio de Ingeniería Ambiental de la USFQ (LIA-USFQ), los mismos que se basan en las técnicas del Standard Methods de la AWWA. Los parámetros que se determinaron fueron: Sólidos Totales (ST), Sólidos Volátiles (SV), Sólidos Suspendidos Totales (SST), Sólidos Suspendidos Volátiles (SSV), Demanda Química de Oxígeno (DQO) total y soluble, nitrato, amonio, oxígeno disuelto, $\mathrm{pH}$, conductividad y turbidez.

\section{Biofiltro de arena}

El estudio de purificación de los efluentes de las Lagunas 4 y 5 se realizó en un biofiltro de arena a escala laboratorio, instalado y puesto en operación para el tratamiento del POME depurado en un estudio anterior [20]. El biofiltro consiste en un recipiente de vidrio de las siguientes dimensiones: $100 \mathrm{~cm}$ de largo, $15 \mathrm{~cm}$ de alto, y $30 \mathrm{~cm}$ de ancho. El biofiltro se encuentra subdividido a lo ancho en tres secciones: dos de $11 \mathrm{~cm}$ y una de $8 \mathrm{~cm}$ (Figura 1). El filtro contiene $26 \mathrm{~L}$ de arena con un espesor del lecho de $10 \mathrm{~cm}$. La arena presenta una porosidad de $40 \%$ lo que corresponde a un volumen de agua en el filtro de $10 \mathrm{~L}$. Adjunto al biofiltro se dispone un tanque de alimentación (3 L de volumen) para la recirculación del líquido al biofiltro. El agua se coloca en este recipiente y por medio de una bomba sumergible fluye al biofiltro con un caudal de $2.67 \mathrm{~L} \mathrm{~h}^{-1}$. El líquido atraviesa la arena a una velocidad de filtración de $24 \mathrm{~cm} \mathrm{~h}^{-1}$ por la primera y segunda sección y a $33 \mathrm{~cm}$ $\mathrm{h}^{-1}$ por la tercera sección (Figura 2 ). El agua tarda 3.8 horas en pasar el biofiltro y se descarga al tanque de alimentación donde permanece 1.1 horas antes de retornar al biofiltro. Mediante una bomba de aire se suministra oxígeno al tanque de alimentación.

El biofiltro operó durante 294 días divididos en tres etapas que se describen a continuación y se resumen en la Tabla 1:

\section{Primera Etapa}

La primera etapa correspondió al intervalo desde el día 1 al 84. Durante los primeros 33 días de funcionamiento, el reactor se alimentó con una muestra de agua residual del efluente de la Laguna 4 (L4) cuya caracterización se presenta en la Tabla 3. Posteriormente se removió los sólidos sedimentables de esta muestra, disminuyendo la carga orgánica y obteniendo una nueva caracterización (Tabla 3) con la cual se trabajó desde el día 34 al 84.

En esta etapa se alimentó al biofiltro un volumen de 650 $\mathrm{mL} \mathrm{d}^{-1}$ de agua residual $(50 \%)$ y medio basal mineral con glucosa, MBMg, (50\%). El tiempo de residencia hidráulico de esta etapa fue de 20 días en total, dividido en 13.3 días en el biofiltro y 6.7 días en el recipiente de recirculación. Los 3 litros de agua que se encontraban en el tanque de alimentación estuvieron en constante aireación por medio de aireadores para mantener el OD entre 2 y $4 \mathrm{mg} \mathrm{L}^{-1}$. Antes de la alimentación, se retiró el mismo volumen de agua del efluente del filtro para mantener constante el volumen en el sistema.

\section{Segunda Etapa}

Esta etapa duró desde el día 85 al 182. Durante esta etapa se alimentó al sistema la muestra del efluente de la Laguna 5 con remoción de sólidos sedimentables (L5s), cuya caracterización se presenta en la Tabla 3. El volumen, la forma de alimentación y el tiempo de residencia se mantuvieron iguales que en la primera etapa. En esta etapa se inició el proceso de desnitrificación a partir del día 85, para lo cual fue necesario un ambiente anóxico, por lo que se aplicaron intervalos de $12 \mathrm{~h}$ de aireación $(8 \mathrm{H} 00$ - 20H00) y 12 h de no aireación $(20 \mathrm{H} 00$ 8 H00). Posteriormente, a partir del día 120 hasta el día 182 se amplió el tiempo de no aireación a 16 h $(20 \mathrm{H} 00$ - 12H00) y el período de aireación fue de 8 h (12H00 20H00).

\section{Tercera Etapa}

La tercera y última etapa duró desde el día 183 al 294. El biofiltro se alimentó únicamente con la muestra L5s desde el día 183 hasta el día 224. El volumen de alimentación se redujo a $325 \mathrm{~mL} \mathrm{~d}^{-1}$, generando un tiempo de residencia de 40 días (26.6 días en el filtro y 13.4 días en el tanque de alimentación). El tiempo de aireación fue de 8 h (8H00 a 16H00). A partir del día 224 se alimentó solo $\mathrm{MBMg}$ con concentraciones de DQO y amonio similares a la de L5s (Tabla 2).

\section{Resultados y Discusión}

\section{Caracterización del agua residual}

La composición de las muestras de agua residual de las L4, L4s y L5s se resume en la Tabla 3.

El pH se encuentra entre 7-8 valores los que se encuentran dentro del rango permisible para descarga a cuerpos de agua dulce de acuerdo a la normativa ambiental ecuatoriana [21] y son adecuados para el crecimiento de microorganismos nitrificantes y desnitrificantes. La concentración de OD en las dos lagunas es baja, lo cual se debe a la alta concentración de materia orgánica responsable del consumo del mismo [4]. La conductividad es una medida indirecta de los sólidos totales disueltos, la cual se encuentra en un rango entre 4 a $5 \mathrm{mS} \mathrm{cm}^{-1}$. La turbidez es ocasionada por la dispersión coloidal o la presencia de partículas en suspensión. La elevada cantidad de sólidos en el agua hace que la turbidez se encuentre fuera del rango de detección para la L4; por lo tanto, para evitar la saturación del filtro se removieron los sólidos sedimentables de las L4 y L5 reduciendo su 


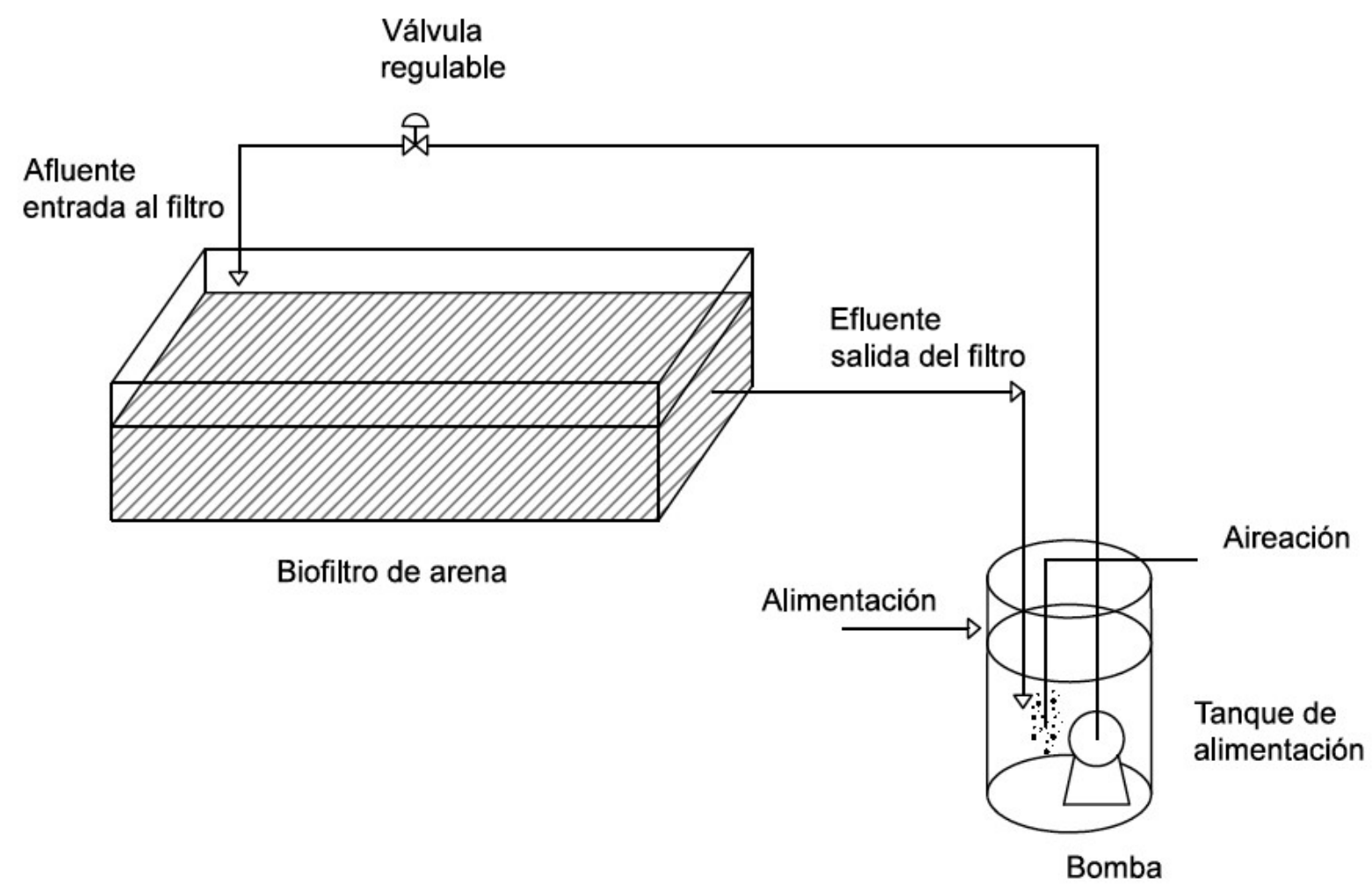

Figura 1: Esquema del biofiltro para purificación de efluentes de las Lagunas 4 y 5.

Afluente

entrada al filtro

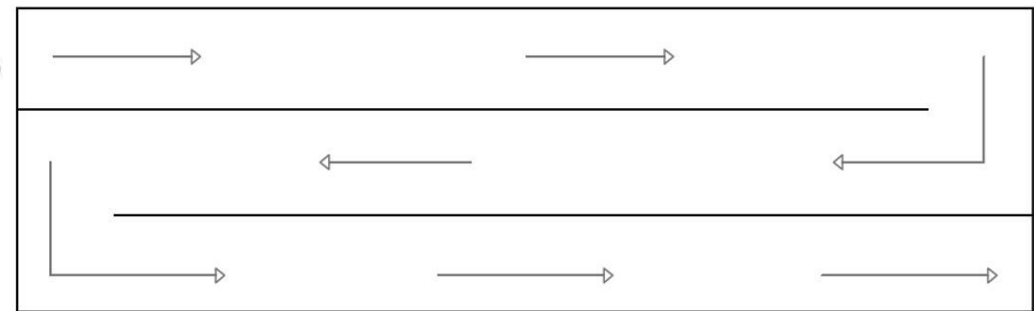

Efluente salida del filtro

Figura 2: Vista superior del biofiltro de arena para tratamiento de efluentes de las Lagunas 4 y 5 . 
Tabla 1: Etapas de operación del biofiltro.

\begin{tabular}{|c|c|c|c|c|}
\hline \multirow[t]{2}{*}{ Etapa } & \multirow{2}{*}{$\begin{array}{c}\text { Duración } \\
\text { día }\end{array}$} & \multicolumn{2}{|c|}{ Alimentación } & \multirow{2}{*}{$\begin{array}{l}\text { Aireación } \\
\text { horas } d^{-1}\end{array}$} \\
\hline & & $\mathrm{mL} \mathrm{d}^{-1}$ & $\begin{array}{l}\text { \% MBMg - } \\
\text { \% Laguna* }\end{array}$ & \\
\hline \multirow{2}{*}{ Primera } & 1 a 33 & 650 & $50 / 50-\mathrm{L} 4$ & 24 \\
\hline & 34 a 84 & 650 & $50 / 50-\mathrm{L} 4 \mathrm{~s}$ & 24 \\
\hline \multirow{2}{*}{ Segunda } & 85 a 120 & 650 & $50 / 50-\mathrm{L} 5 \mathrm{~s}$ & 12 \\
\hline & 120 a 182 & 650 & $50 / 50-L 5 s$ & 8 \\
\hline \multirow{2}{*}{ Tercera } & 183 a 224 & 325 & $100-\mathrm{L} 5 \mathrm{~s}$ & 8 \\
\hline & 225 a 294 & 325 & $100-\mathrm{MBMg}$ & 8 \\
\hline
\end{tabular}

${ }^{*}$ Medio basal mineral con glucosa (MBMg); Laguna 4 (L4); Laguna 4 con remoción de sólidos (L4s); Laguna 5 con remoción de sólidos (L5s).

Tabla 2: Composición del medio basal mineral con glucosa (MBMg).

\begin{tabular}{|c|c|c|}
\hline Etapa & $1^{r a}$ y $2^{d a}$ & $3^{r a}$ \\
\hline Compuesto & \multicolumn{2}{|c|}{$\mathrm{g} \mathrm{L}^{-1}$} \\
\hline $\mathrm{NH}_{4} \mathrm{Cl}$ & 0.280 & 0.790 \\
\hline $\mathrm{MgSO}_{4}, 7 \mathrm{H}_{2} \mathrm{O}$ & 0.626 & 0.626 \\
\hline $\mathrm{CaCl}_{2}$ & 0.010 & 0.010 \\
\hline $\begin{array}{l}\text { Estracto de } \\
\text { levadura }\end{array}$ & 0.010 & 0.010 \\
\hline $\mathrm{NaHPO}_{4}$ & 0.148 & 0.148 \\
\hline Glucosa & 0.178 & 0.870 \\
\hline $\mathrm{NaNO}_{3}$ & 0.012 & 0.012 \\
\hline $\mathrm{NaHCO}_{3}$ & 3.000 & 3.000 \\
\hline $\begin{array}{l}\text { Solución de } \\
\text { elemento traza }\end{array}$ & $1 \mathrm{~mL} \mathrm{~L}^{-1}$ & $1 \mathrm{~mL} \mathrm{~L}^{-1}$ \\
\hline $\begin{array}{r}{ }^{1} \mathrm{H}_{3} \mathrm{BO}_{3}, \mathrm{Fe} \\
\left(\mathrm{NH}_{4}\right)_{6} \mathrm{Mo} \\
\mathrm{CoCl}_{2} 6 \mathrm{H}_{2} \mathrm{O}, \\
\mathrm{NaSeO}_{3} 5 \mathrm{H}_{2} \mathrm{O}\end{array}$ & $\begin{array}{l}\mathrm{Cl}_{2}, 6 \mathrm{H}_{2} \mathrm{O}, \\
\text { DTA, Resa }\end{array}$ & $\begin{array}{l}, \mathrm{MnCl}_{2}, \\
{ }_{3} 6 \mathrm{H}_{2} \mathrm{O} \\
\mathrm{SO}_{4} 5 \mathrm{H}_{2} \mathrm{O}, \\
\text { in, } \mathrm{HCl} 36 \%\end{array}$ \\
\hline
\end{tabular}

turbidez a 884 y 173 NTU, respectivamente. La DQO total en las muestras de agua L4, L4s, y L5s es considerablemente superior al límite máximo permisible de la norma ambiental de $200 \mathrm{mg} \mathrm{L}^{-1}$. Consecuentemente con la remoción de sólidos sedimentables la DQO bajó de 3705 para L4 a $2171 \mathrm{mg} \mathrm{L}^{-1}$ para la muestra L4s y a $937 \mathrm{mg} \mathrm{L}^{-1}$ para la L5s.

Los sólidos totales en las muestras L4, L4s y L5s presentan concentraciones elevadas aun cuando se remueven los sólidos sedimentables, los valores sobrepasan el límite máximo permisible de $1600 \mathrm{mg} \mathrm{L}^{-1}$. Los sólidos volátiles presentan concentraciones de $7490 \mathrm{mg} \mathrm{L}^{-1}$ en la L4, $1130 \mathrm{mg} \mathrm{L}^{-1}$ en la L4s y $780 \mathrm{mg} \mathrm{L}^{-1}$ en la L5s. Los SST representan el material particulado presente en la muestra, una vez elimidados los sólidos sedimentables de la L4 y L5 la concentración de SST es de 290 y $140 \mathrm{mg} \mathrm{L}^{-1}$ respectivamente. Los SSV representan una medida indirecta de la biomasa, siendo estos 270 y 80 $\mathrm{mg} \mathrm{L}^{-1}$ para L4s y L5s, respectivamente. La relación SSV/SST establece el comportamiento de las bacterias activas útiles para la degradación efectiva de materia orgánica ya que estos valores se asocian a la biomasa formada. Para un tratamiento biológico esta relación debe ser alrededor de 0.7 [22]. En el caso de la L4s este valor es de 0.93 , y 0.57 en la L5s, lo cual refleja que es factible un tratamiento biológico para remover la materia orgánica.

La L4s presenta una concentración de amonio de 188 $\mathrm{mg} \mathrm{L}^{-1}$ y en la L5s aumenta a $266 \mathrm{mg} \mathrm{L}^{-1}$ debido a un proceso de amonificación que consiste en la asimilación de proteínas y aminoácidos para formar amonio [5]. Por: Como resultado del proceso de amonificación que consiste en la asimilación de proteínas y aminoácidos para formar amonio [5], el efluente de las lagunas L4, L4s, L5s presentan una concentración de nitrógeno amoniacal elevado de 317, 146 y $207 \mathrm{mg} \mathrm{L}^{-1}$ respectivamente. Estos valores son muy superiores a lo requerido por la norma ambiental de $30 \mathrm{mg} \mathrm{L}^{-1}$.

\section{Eliminación de contaminación orgánica}

La Figura 3 muestra los resultados de la reducción de la materia orgánica en términos de la DQO total durante las diferentes etapas de funcionamiento del biofiltro. Durante los primeros 33 días de la primera etapa, se alimentaron $650 \mathrm{~mL} \mathrm{~d}^{-1}$ (tiempo de residencia de 20 días) correspondiente a la mezcla de $50 \%$ de MBMg y $50 \%$ de L4, con una concentración de DQO de $1947 \mathrm{mg} \mathrm{L}^{-1}$. Después del tratamiento en el biofiltro la concentración en el efluente bajó a alrededor de $400 \mathrm{mg} \mathrm{L}^{-1}$. Durante esta etapa, la turbidez bajó de 1220 hasta 3.74 NTU. Para evitar una posterior saturación debida a la elevada carga de sólidos suspendidos, a partir del día 34 hasta el día 84 se alimentó L4s con una concentración de DQO de $1180 \mathrm{mg} \mathrm{L}^{-1}$. Después de 22 días la DQO en el efluente disminuyó a $350 \mathrm{mg} \mathrm{L-1,} \mathrm{logrando} \mathrm{una} \mathrm{re-}$ moción de $70 \%$.

En la segunda etapa, que fue desde el día 85 hasta el día 182, se alimentó $50 \%$ de MBMg y $50 \%$ L5s cuya DQO fue de $558 \mathrm{mg} \mathrm{L}^{-1}$. Durante esta etapa se operó en intervalos alternados de aireación y no aireación. Se observó una disminución de la DQO en el tiempo hasta llegó a estabilizarse en un rango de 224 a $237 \mathrm{mg} \mathrm{L}^{-1}$ para el intervalo de aireación y entre 202 a $217 \mathrm{mg} \mathrm{L}^{-1}$ en el intervalo de no aireación. Se alcanzó una eficiencia del $64 \%$.

Desde el día 183 al 224 de la tercera etapa, se alimentaron $325 \mathrm{~mL} \mathrm{~d}^{-1}$ (tiempo de residencia de 40 días) 
Tabla 3: Caracterización de parámetros físico-químicos de muestras obtenidas de lagunas anaeróbicas y límites máximos permisibles por el Texto Unificado de Legislación Ambiental Secundaria del Ministerio de Ambiente del Ecuador.

\begin{tabular}{cccccc}
\hline Parámetro & Unidad & $\begin{array}{c}\text { Laguna } 4 \\
\text { sin remoción } \\
\text { de sólidos } \\
\text { sedimentables } \\
\text { L4 }\end{array}$ & $\begin{array}{c}\text { Laguna 4 } \\
\text { sin remoción } \\
\text { de sólidos } \\
\text { sedimentables } \\
\text { LH }\end{array}$ & $\begin{array}{c}\text { Laguna 5 } \\
\text { sin remoción } \\
\text { de sólidos } \\
\text { sedimentables } \\
\text { L5s }\end{array}$ & $\begin{array}{c}\text { Límites de } \\
\text { descarga a } \\
\text { un cuerpo } \\
\text { de agua } \\
\text { dulce* }\end{array}$ \\
\hline Oxígeno & $\mathrm{mg} \mathrm{L}^{-1}$ & 0.57 & 7.60 & 8.0 & $6-9$ \\
disuelto, OD & $\mathrm{mS} \mathrm{cm}^{-1}$ & 5.88 & 0.30 & 1.61 & - \\
Conductividad & $\mathrm{NTU}^{*}$ & - & 4.28 & 4.60 & - \\
Turbidez & $\mathrm{mg} \mathrm{L}^{-1}$ & 3705 & 884 & 173 & - \\
DQO total & $\mathrm{mg} \mathrm{L}^{-1}$ & - & 2171 & 937 & 200 \\
DQO soluble & $\mathrm{mg} \mathrm{L}^{-1}$ & 13320 & 1312 & 703 & - \\
ST & $\mathrm{mg} \mathrm{L}^{-1}$ & 7490 & 1130 & 2890 & 1600 \\
SV & $\mathrm{mg} \mathrm{L}^{-1}$ & 2290 & 290 & 780 & - \\
SST & $\mathrm{mg} \mathrm{L}^{-1}$ & 1990 & 270 & 140 & 130 \\
SSV & $\mathrm{mg} \mathrm{L}^{-1}$ & 39 & 56 & 80 & - \\
Nitratos & $\mathrm{mg} \mathrm{L}^{-1}$ & 317 & 146 & 6 & - \\
Nitrógeno amoniacal & $\mathrm{mg} \mathrm{L}^{-1}$ & - & - & 207 & 30 \\
TKN & & & - & 15 \\
\hline
\end{tabular}

*Texto Unificado de Legislación Ambiental Secundaria del Ministerio de Ambiente.

Registro oficial 386 del 4 de noviembre de 2015, Tabla 9

de únicamente L5s con una concentración de DQO de $937 \mathrm{mg} \mathrm{L}^{-1}$. La eficiencia de remoción se estabilizó en $41 \%$ con concentraciones promedio de $551 \mathrm{mg} \mathrm{L}^{-1}$ a la salida del biofiltro. La disminución en la eficiencia de remoción se puede atribuir a la menor biodegradabilidad que presenta L5s en comparación con la mezcla $50 \%$ MBMg y $50 \%$ L5s. Substancias como grasas y aceites, y sus productos de degradación son menos biodegradables que la glucosa [23]. El agua residual de la extracción de palma presenta elevadas concentraciones de grasas y aceites [2] por lo que la degradación biológica de la materia orgánica de L5s resulta menos eficiente que la del MBMg. Entre los días 218 y 318 se alimentó solo MBMg con una concentración de DQO de 922 $\mathrm{mg} \mathrm{L}^{-1}$, llegando hasta un porcentaje de remoción del $85 \%$ (Figura 3), el cual es mayor al de los de las etapas anteriores. Esto se debe a que la fuente de carbono es glucosa, la cual se degrada fácilmente [24], y a que durante el período anóxico ocurre desnitrificación, donde parte de la materia orgánica es degradada [12].

\section{Nitrificación}

Durante la primera etapa se alimentó concentraciones de 177.5 y $188.5 \mathrm{mg} \mathrm{L}^{-1}$ de $\mathrm{NH}_{4}^{+}$(Figura 4). Durante este periodo se mantuvo una aireación constante para promover la nitrificación. Se observó un incremento de la concentración de $\mathrm{NO}_{3}^{-}$hasta un valor de $944 \mathrm{mg} \mathrm{L}^{-1}$ (Figura 5) y una remoción de $\mathrm{NH}_{4}^{+}$del $44 \%$. En este periodo la cantidad de materia orgánica particulada retenida por el filtro fue elevada, y su amonificación podría explicar la tendencia al incremento de la concentración de amonio a la salida del filtro hasta el día 91 (Figura 4) $[7,8]$.
En la segunda etapa el tiempo de aireación pasó de 24 a $12 \mathrm{~h} \mathrm{~d}^{-1}$ entre los días 85 a 119 , y a $8 \mathrm{~h} \mathrm{~d}^{-1}$ entre los días 120 a 182. Durante los primeros días de esta etapa se observó una menor remoción de amonio. Sin embargo, a partir del día 91 hubo una tendencia a disminuir la concentración de amonio llegando a porcentajes de remoción del $74 \%$. El cambio en el régimen de aireación afectó solo hasta que los microorganismos se adaptaron y no se observó inhibición de la nitrificación (Figura 4). La alimentación durante esta etapa tuvo una concentración de DQO de $558 \mathrm{mg} \mathrm{L}^{-1}$, dando una relación $\mathrm{DQO} / \mathrm{N}-\mathrm{NH}_{4}^{+}$de 4.1 , la cual es viable para la nitrificación ya que según estudios se ha demostrado inhibición de la nitrificación en relaciones de $\mathrm{DQO} / \mathrm{N}-\mathrm{NH}_{4}^{+}$ superiores a $5[8]$.

En la tercera etapa se aumentó la concentración de amonio en la alimentación a $266 \mathrm{mg} \mathrm{L}^{-1}$. En un inicio únicamente con agua de L5s (entre los días 182 y 217), logrando una remoción del $66 \%$ de amonio. Posteriormente se alimentó solo con MBMg que contenía la misma concentración de amonio y una DQO de 922 mg $\mathrm{L}^{-1}$ (entre los días 218 y 318), presentando una relación $\mathrm{DQO} / \mathrm{N}-\mathrm{NH}_{4}^{+}$de 4.5. Así mismo se logró una elevada remoción de amonio del $87 \%$ (Figura 4) a pesar de que el tiempo de aireación en este período fue de solo 8 h.

\section{Desnitrificación}

En la Figura 5 se observa que en la segunda etapa, a partir del día 120, existe una pronunciada disminución en la concentración de nitrato a la salida del biofiltro; esto po- 


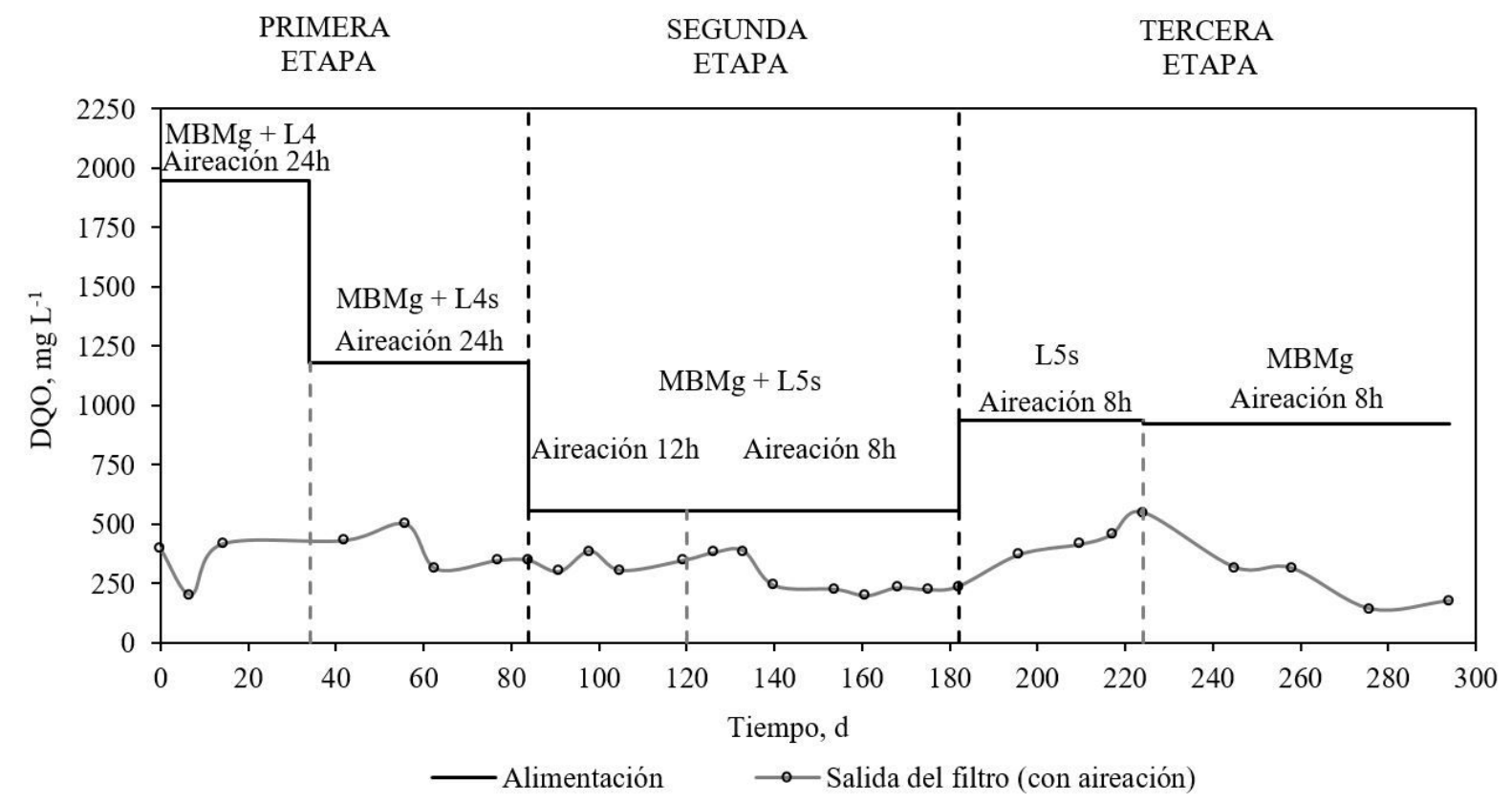

Figura 3: Concentración de la DQO total con el tiempo para las diferentes etapas de funcionamiento. Leyenda: (-) alimentación; (o) salida del filtro (con aireación).

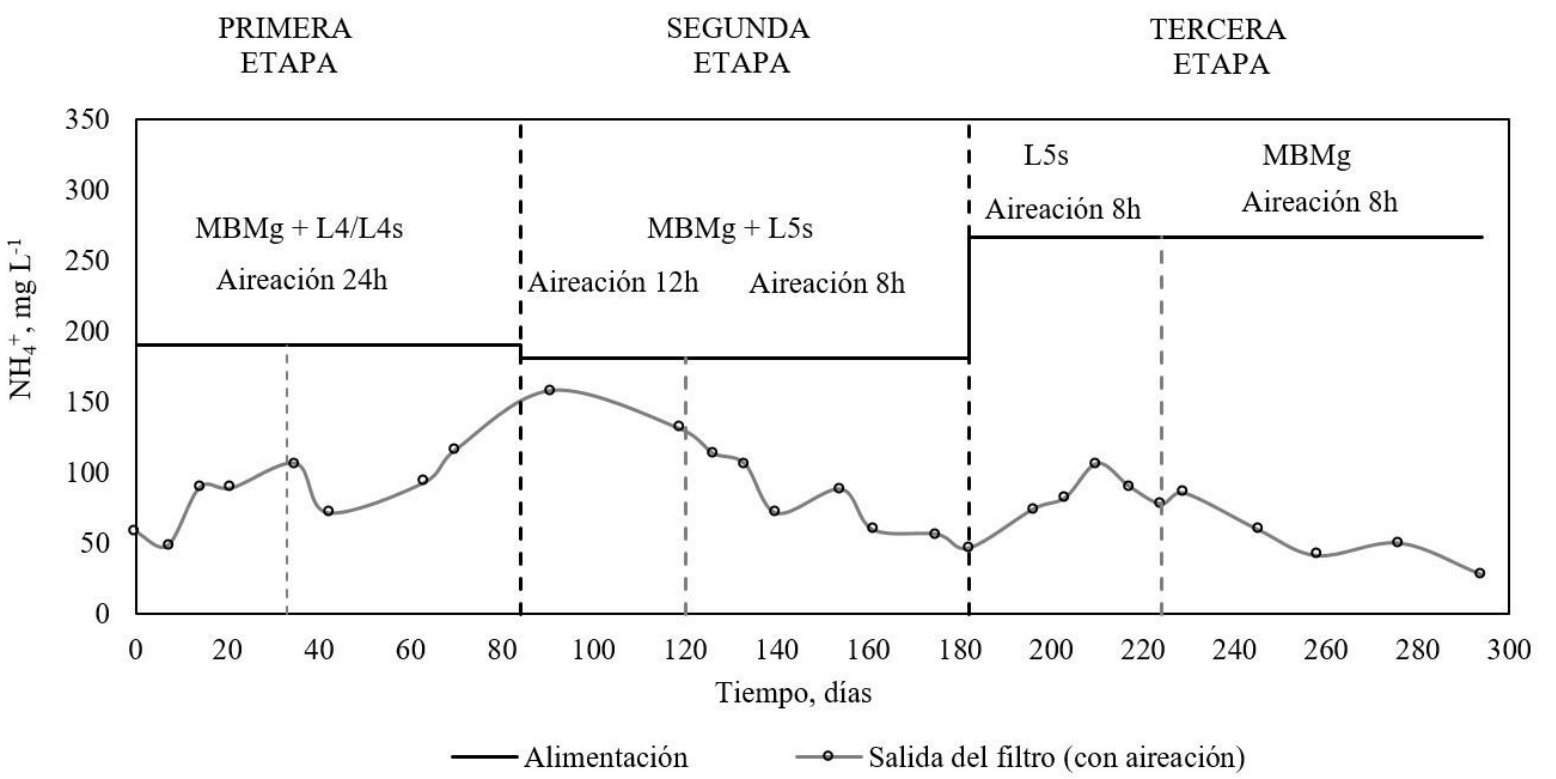

Figura 4: Concentración de amonio en función del tiempo durante la etapa de aireación. Leyenda: (-) alimentación con MBMg y L4/L4s/L5s, (o) salida del filtro (con aireación). 


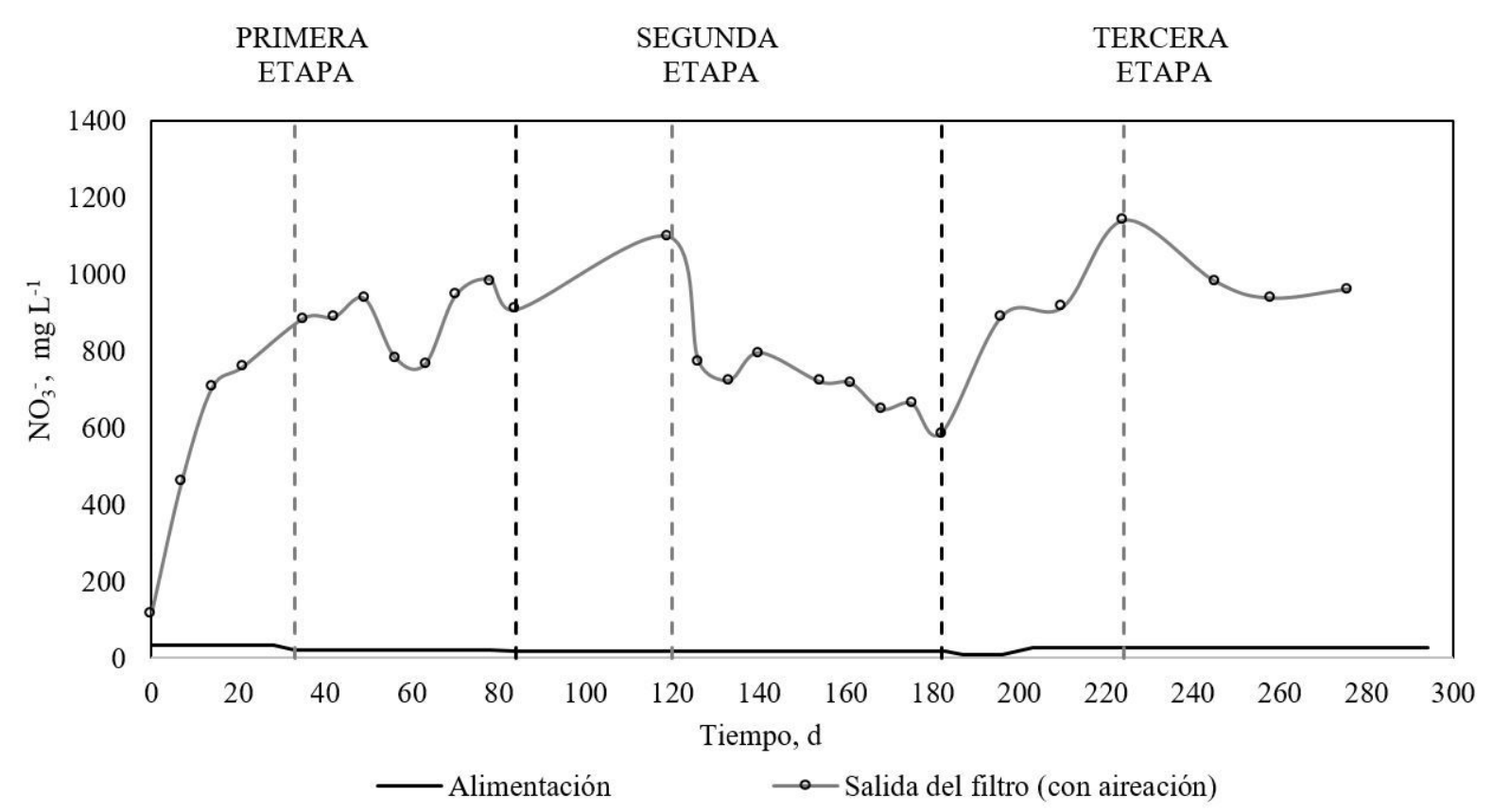

Figura 5: Concentración de nitrato en función del tiempo. Leyenda: (-) alimentación; (o) salida del filtro (con aireación).

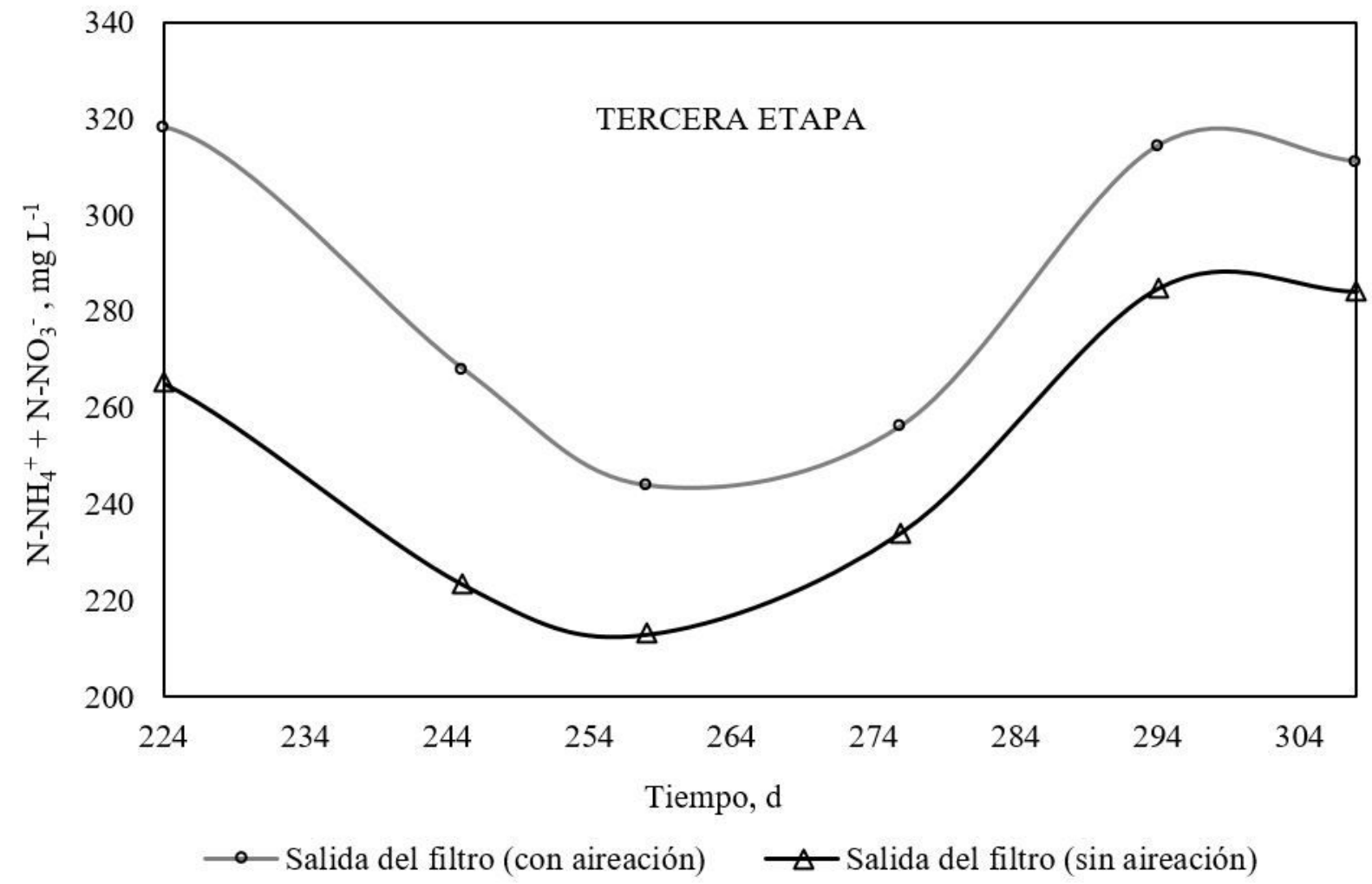

Figura 6: Concentración de nitrógeno inorgánico total $\left(\mathrm{N}-\mathrm{NH}_{4}^{+}+\mathrm{N}-\mathrm{NO}_{3}^{-}\right)$en función del tiempo durante la etapa de aireación y sin aireación. Leyenda: (o) Salida del filtro (intervalo con aireación), $(\Delta)$ Salida del filtro (intervalo sin aireación). 


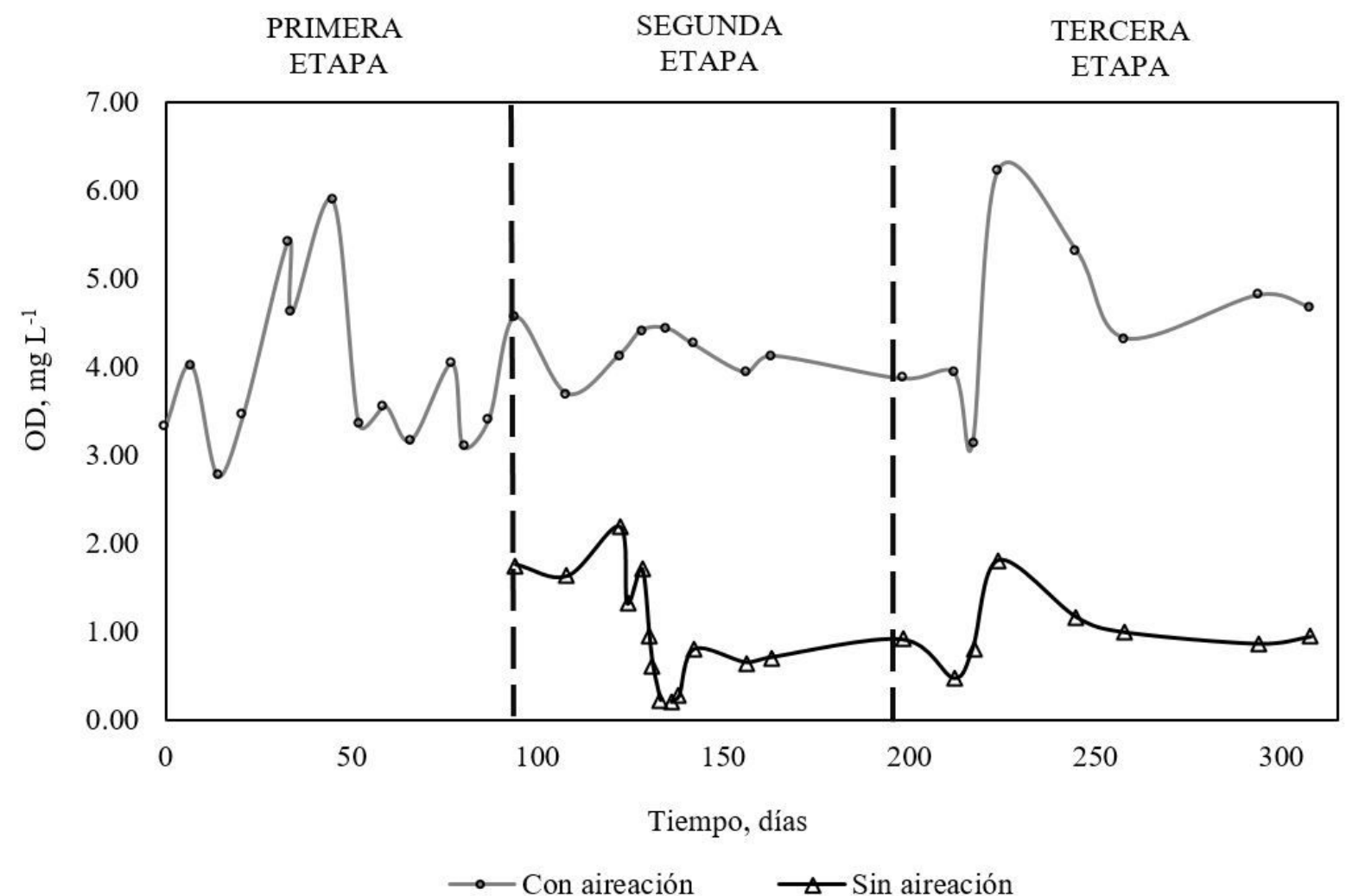

Figura 7: Concentración de oxígeno disuelto en función del tiempo. Leyenda: (o) Intervalo con aireación $(\Delta)$ Intervalo sin aireación.

dría ser el resultado del aumento del intervalo anóxico de 8 a $16 \mathrm{~h} \mathrm{~d}^{-1}$, lo mismo que promueve la desnitrificación [12]. La eficiencia de la desnitrificación depende de la disponibilidad de una fuente de carbono [25] por lo que para la tercera etapa se optó por utilizar el método de Ludzack-Ettinger modificado de predesnitrificación [4], para lo cual se alimentó al inicio del período sin aireación para evitar la limitación por falta de carbono.

La Figura 6 presenta la concentración de nitrógeno inorgánico total $\left(\mathrm{N}-\mathrm{NH}_{4}^{+}+\mathrm{N}-\mathrm{NO}_{3}^{-}\right)$a la salida del filtro durante la tercera etapa, para los intervalos con aireación y sin aireación. Se observa que la concentración de nitrógeno inorgánico total en el intervalo anóxico es en promedio $13 \%$ menor que durante el intervalo aireación, lo que indica que la desnitrificación no es completa. La relación DQO/N en la alimentación del filtro durante la tercera etapa corresponde a un valor de 4.5, lo que implica una desnitrificación parcial por escasez de carbono [13]. Así mismo, la limitada desnitrificación pudo deberse a que en ciertos periodos la concentración de OD no estuvo dentro del rango entre 0.2 y $0.5 \mathrm{mg}$ $\mathrm{L}^{-1}$ que, según la literatura, es el mejor rango para que ocurra desnitrificación [11] (ver Figura 7). En presencia de oxígeno se inhibe la enzima óxido nitroso reductasa, encargada de la reducción a N2 [27].

\section{Conclusiones}

Mediante un biofiltro se logró remover materia orgánica y compuestos nitrogenados de agua residual pretratada en lagunas anaeróbicas de una extractora de aceite crudo de palma. El biofiltro fue operado en tres etapas y al finalizar la tercera etapa se obtuvieron porcentajes de remoción entre el 41 al $85 \%$ para DQO, y entre 66 a $87 \%$ para $\mathrm{NH}_{4}^{+}$. La eficiencia de la eliminación de DQO y amonio depende de la biodegradabilidad de la materia orgánica. Cuando se alimentó agua residual de la laguna anaeróbica 5 (L5s) la remoción de DQO y amonio fue del $41 \%$ y $66 \%$ respectivamente; por otra parte, cuando se alimentó medio basal mineral con glucosa (MBMg) la eficiencia aumentó correspondientemente a $85 \%$ y $87 \%$. Estos resultados indican la viabilidad del uso de biofiltros para la depuración de efluentes industriales con niveles intermedios de contaminación (DQO $=558-1947 \mathrm{mg} \mathrm{L}^{-1} \mathrm{y} \mathrm{NH}_{4}^{+}=181-266 \mathrm{mg} \mathrm{L}^{-1}$ ), logrando cumplir con la normativa ambiental nacional de descarga a cuerpos de agua dulce de DQO $=200 \mathrm{mg}$ $\mathrm{L}^{-1}$, mientras que los niveles de amonio se encuentran ligeramente sobre la norma. En comparación con sistemas convencionales de remoción de materia orgánica y amonio como el tratamiento por lodos activados, la biofiltración presenta ventajas económicas por la menor inversión en equipamiento, sin embargo su aplicabilidad está limitada por la disponibilidad de área para la instalación de los biofiltros. 
Por otro lado, la desnitrificación ocurre de manera limitada y se manifiesta durante la tercera etapa con una concentración de nitrogéno inorgánico total $13 \%$ menor en el intervalo anóxico en comparación con el intervalo aireado. La baja remoción de nitrato puede estar influenciada por una relación $\mathrm{DQO} / \mathrm{N}$ de 4.5 en la alimentación del biofiltro, la cual está por debajo del nivel óptimo para desnitrificación entre 5 y 6 y por una concentración de oxígeno disuelto en el intervalo anóxico por sobre el rango adecuado de 0.2 y $0.5 \mathrm{mg} \mathrm{L}^{-1}$. La concentración de $\mathrm{N}-\mathrm{NO}_{3}^{-}$del efluente del biofiltro se encuentra fuera de la norma ambiental, por lo que se requiere de futuros desarrollos para optimizar la desnitrificación de este sistema.

\section{Agradecimientos}

Agradecemos a las autoridades de la Universidad San Francisco de Quito por el apoyo en el desarrollo de este trabajo científico. Nuestro agradecimiento también para los representantes de la extractora de aceite crudo de palma por la apertura y ayuda durante el desarrollo del proyecto.

\section{Referencias}

[1] Campbell, J., \& Jeffries, B. (2013). Palm Oil Buyers Scorecard: Measuring the Progress of Palm Oil Buyers. World Wildlife Fund-Report, 1-62.

[2] Rupani, P., \& Singh, R. (2010). Review of current palm oil mill effluent (POME) treatment methods: Vermicomposting as a sustainable practice. World Appl Sci. 11(1): 70-81.

[3] Escaler, I., \& Mujeriego, R. (2001). Eliminación biológica de nutrientes ( nitrógeno y fósforo ) mediante un proceso discontinuo de fangos activados. Ingeniería del Agua 8(1): 67-77.

[4] Claros, J. (2012). Estudio del proceso de nitrificación y desnitrificación vía nitrito para el tratamiento biológico de corrientes de agua residual con alta carga de nitrógeno amoniacal. Universidad Politécnica de Valencia, Tesis doctoral: Valencia.

[5] Metcalf \& Eddy. (2014). Wastewater Engineering Treatment and Reuse. 5th Edition AECOM. New York.

[6] González, M., \& Saldarriaga, J. (2008). Remoción biológica de materia orgánica, nitrógeno y fósforo en un sistema tipo anaerobio-anóxico-aerobio. EIA. 10: 45-53.

[7] Sánchez, J., \& Sanabria J. (2009). Metabolismos microbianos involucrados en procesos avanzados para la remoción de Nitrógeno, una revisión prospectiva. Rev Colomb Biotecnol. 11(2): 114-124.

[8] Ling, J., \& Chen, S. (2005). Impact of organic carbon on nitrification performance of different biofilters. Aquacultural Engineering 33: 150Ű162.
[9] Li, W., Liang, X., Lin, J., \& Liu, L. (2013). Competition of autotrophic and heterotrophic denitrification in anaerobic biofilm wastewater treatment process. J Chem Pharm Res. 5(12): 30-35.

[10] Lolmede, J., Vidart, T., \& Tejero, I. (2000). Tratamiento de agua residual con elevado contenido de nitratos utilizando reactores biomembrana aireados. Ingeniería del Agua. 7(3): 243-254.

[11] Won, S., Jeon, D., Kwag, J., Kim, J., \& Ra, C. (2015). Nitrogen Removal from Milking Center Wastewater via Simultaneous Nitrification and Denitrification Using a Biofilm Filtration Reactor. Asian Australas. J. Anim. Sci. 28(6): 896-902.

[12] Münch, E., Lant, P., \& Keller, J. (1996). Simultaneous nitrification and denitrification in bench-scale sequencing batch reactors. Wat. Res. 30(2): 277-284.

[13] Xie, L., Chen, J., Wang, R., \& Zhou, Q. (2012). Effect of carbon source and COD/NO3-N ratio on anaerobic simultaneous denitrification and methanogenesis for high-strength wastewater treatment. J Biosci Bioeng. 113(6): 759-764.

[14] Ghaniyari-Benis, S., Borja, R., Magheri, M., Goodarzi, V., \& Tooyserkani, Z. (2010). Effect of adding nitrate on the performance of a multistage biofilter used for anaerobic treatment of high strength wastewater. J Chem Inf Model. 156(2) 250 -256.

[15] Henze, M., Loosdrecht, M., Ekama, G., \& Brdjanovic, D. (2008). Biological Wastewater Treatment: Principles, Modelling and Design. IWA Publishing.

[16] Bratieres, K., Fletcher, T.D., Deletic, A., \& Zinger, Y. (2008). Nutrient and sediment removal by stormwater biofilters: A large-scale design optimisation study. Wat. Res. 42(14): 3930-3940.

[17] García, C., \& Gonzales, S. (2015). Desempeño de un filtro biológico combinado e indicadores biológicos en el tratamiento de aguas residuales. Congreso Nacional de Ingeniería Sanitaria y Ciencias Ambientales, 12, Morelia, 21-24 mar. 2000: memorias técnicas. 1-8.

[18] Feng, Q., Cao, J., Chen, L., Guo, C., Tan, J., \& Xu, H. (2011). Simultaneous nitrification and denitrification at variable $\mathrm{C} / \mathrm{N}$ ratio in aerobic granular sequencing batch reactors. Journal of Food Agriculture and Environment. 9(3\&4): 1135-1140.

[19] Pazmiño G. (2015). Estudio de la generación de gas metano y remoción de carga orgánica en las lagunas anaerobias de la planta de tratamiento de aguas residuales de una extractora de aceite crudo de palma. Universidad San Francisco de Quito, Tesis de Ingeniería Ambiental: Quito.

[20] Narvaez E. (2015). Estudio sobre la recirculación de agua de producción utilizada para la extracción de aceite crudo de palma. Universidad San Francisco de Quito, Tesis de Ingeniería Ambiental: Quito.

[21] Ministerio del Ambiente del Ecuador. (2002). Norma de Calidad Ambiental y de Descarga de Efluentes: Recurso Agua. Texto Unificado de Legislación Ambiental Secundaria del Ministerio de Ambiente. Libro VI Anexo 1. 
[22] Castro, F., Fernández, N., \& Chávez, M. (2008). Diminution of the COD in formation waters using bacterial stocks. Rev. Téc. Ing. Univ. Zulia. 31(3): 256-265.

[23] Chamorro, G. (2015). Evaluación de una planta de tratamiento de aguas residuales de una empresa de fabricación de quesos. Universidad San Francisco de Quito, Tesis de Ingeniería Ambiental: Quito.

[24] Rijn, J., Tal, Y., \& Schreier, H. (2006). Denitrification in recirculating systems: Theory and applications. Aquacultural Engineering. 34(3): 364-376.

[25] Czerwionka, K., Makinia, J., Kaszubowska, M., Majtacz, J., \& Angowski, M. (2012). Distillery wastes as external carbon sources for denitrification in municipal wastewater treatment plants. Water Sci Technol. 65(9): 1583-1590.

[26] Cervantes, F., Pérez, J., \& Gómez, J. (2000). Avances en la eliminación biológica del nitrógeno de las aguas residuales. Rev Latinoam Microbiol. 42(2): 73-82.

[27] Ellis, K. (1974). Slow sand filtration. Crit Rev Environ Control. 15(4): 315-354.

[28] Rochette F. (2010). Sistema de Intercambio Iónico de Alto Rendimiento para la Remoción de Nitrato. Agua Latinoamérica. 10(11). 